\title{
An Unexpected Cause of Marked Weight Loss Associated with Vomiting in an Adult Man: Gastric Phytobeozar
}

\author{
Marco Vacante, Innocenza Alessandria, Emanuela Cataudella, Rosangela Fichera, Lorenzo Malatino \\ Department of Internal Medicine, University of Catania, Ospedale Cannizzaro, Catania, Italy
}

\section{Doi: 10.12890/2015_000258 - European Journal of Case Reports in Internal Medicine - ๑ EFIM 2015}

Received: $21 / 07 / 2015$

Accepted: 09/08/2015

Published: $16 / 12 / 2015$ How to cite this article: Vacante M, Alessandria I, Cataudella E, Fichera R, Malatino L. An unexpected cause of marked weight loss associated with vomiting
in an adult man: gastric phytobeozar. EJCRIM 2015;2:doi:10.12890/2015_000258

Conflicts of Interests: The authors declare that there are no competing interests.

Patient's Consent: The authors declare they obtained patient's informed consent.

This article is licensed under a Commons Attribution Non-Commercial 4.0 License

\section{ABSTRACT}

Objectives: We present the case of an edentulous 47-year-old farmer referred to our Department of Internal Medicine because of postprandial vomiting, hyporexia, asthenia and weight loss. He ate a mostly vegetarian diet.

Materials and methods: An oesophagogastroduodenoscopy revealed the presence of a phytobezoar at the level of the fundus and body of the stomach. Endoscopic fragmentation and removal of the phytobezoar were unsuccessful and the patient had to undergo open surgery. Results: Recovery was uneventful and free of complications.

Conclusion: Phytobezoars should be taken into account in the differential diagnosis of unexplained vomiting and weight loss.

\section{LEARNING POINTS}

- Bezoars are concretions of indigestible materials located in the gastrointestinal tract.

- Gastric phytobezoars may cause unexplained vomiting and weight loss even in young people.

- The diagnosis of phytobezoars may be complex and endoscopy is helpful in most cases.

\section{KEYWORDS}

Bezoar; edentulism; vomiting; hyporexia; weight loss.

\section{INTRODUCTION}

The term 'bezoar' is derived from the Arabic "bazahr" or "badzehr", which means antidote or counter-poison. Bezoars of animal origin are still used therapeutically in traditional medicine in China and South-East Asia ${ }^{[1]}$. The first case of bezoar in man was described by Baudamant in Paris in $1779^{[2]}$. Bezoars are concretions of indigestible material found in the gastrointestinal tract and are generally classified according to their composition into trichobezoars (hair), phytobezoars (plant material) and pharmacobezoars (pharmaceutical products) ${ }^{[1,3,4]}$. Most phytobezoars consist of indigestible cellulose, tannin, and lignin derived from ingested vegetables and fruits ${ }^{[5]}$. Diospyrobezoar is a type of phytobezoar caused by the ingestion of persimmons ${ }^{[6]}$. Unripe persimmons contain soluble tannin that may polymerize in the stomach due to the acidic environment, thus creating a core facilitating bezoar formation ${ }^{[7]}$. This case report underscores the concept that a synergistic effect may occur between edentulism and a diet rich in fruits and vegetables in inducing phytobezoar formation at an earlier age than generally reported in the literature. 


\section{CASE REPORT}

A 47-year-old patient with a history of heavy alcohol consumption was admitted to our Department of Internal Medicine because of hyporexia, asthenia, weight loss (12 kg over the last 6 months), nausea, postprandial vomiting and pyrosis. He also reported dyspnoea on mild exertion. The patient was edentulous and occasionally wore a denture, worked as a farmer, and had a 40 pack-year history of cigarette smoking. His diet consisted predominantly of fruits and vegetables. On admission, the patient was given omeprazole (40 mg/day). He was afebrile, with normal blood pressure $\left(130 / 80 \mathrm{mmHg}\right.$ ), but with tachycardia (110 bpm); $\mathrm{SaO}_{2}$ on room air was $97 \%$. Physical examination revealed epigastric and right hypochondrial pain. The rest of the physical examination was unremarkable. Laboratory data showed a mild increase in aspartate aminotransferase (AST) $78 \mathrm{U} / \mathrm{l}$ (normal value $<40 \mathrm{U} / \mathrm{l}$ ) and total bilirubin $1.80 \mathrm{mg} / \mathrm{dl}$ (normal value $0.25-1.1 \mathrm{mg} / \mathrm{dl}$ ), while gamma-glutamyl transpeptidase ( $\mathrm{Y}-\mathrm{GT}$ ) $674 \mathrm{U} / \mathrm{l}$ (normal value $<50 \mathrm{U} / \mathrm{l}$ ), ferritin $1126 \mathrm{ng} / \mathrm{ml}$ (normal value $23-336 \mathrm{ng} / \mathrm{ml}$ ), lactate dehydrogenase (LDH) $778 \mathrm{U} / \mathrm{l}$ (normal value 230-460 U/I), vitamin B12 1592 pg/ml (normal value 180-914 pg/ml) and $\beta 2-\mathrm{microglobulin}$ $2558 \mathrm{ng} / \mathrm{ml}$ (normal value 850-2160 ng/ml) exceeded the upper limits of normal. Since cancer was suspected, possibly localized in the stomach or pancreas, we decided to carry out a CT scan of the abdomen and an oesophagogastroduodenoscopy, in order to exclude cancer as a possible cause of the weight loss, vomiting and hyporexia. The CT scan showed a hypodense intraluminal ovoid mass in the stomach, with a mottled gas pattern within the gastric lumen, associated with wall thickening (Fig. 1). An oesophagogastroduodenoscopy revealed the presence of a phytobezoar $(15 \times 4 \mathrm{~cm})$ located in the fundus and body of the stomach (Fig. 2). The endoscopist tried, but unsuccessfully, to fragment and remove the phytobezoar. The patient was therefore referred to the Department of Surgery for operation; the phytobezoar was then removed from the stomach by gastrotomy (Fig. 3). The patient's postoperative outcome and recovery were uneventful and free of complications. When patient was seen by his primary care provider 3 months after discharge, he was symptomless and had regained the lost weight.

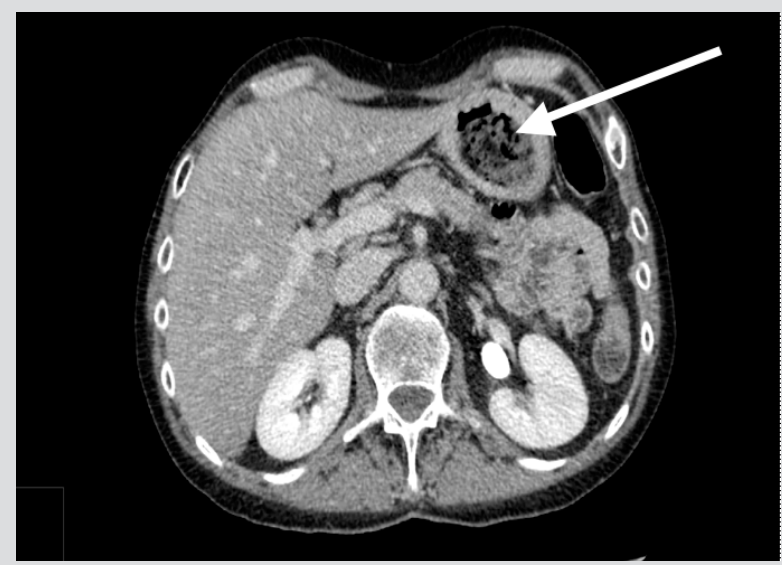

Figure 1: CT scan of the abdomen showing an ovoid intraluminal heterogeneous mass in the stomach, with interspersed gas (arrow)

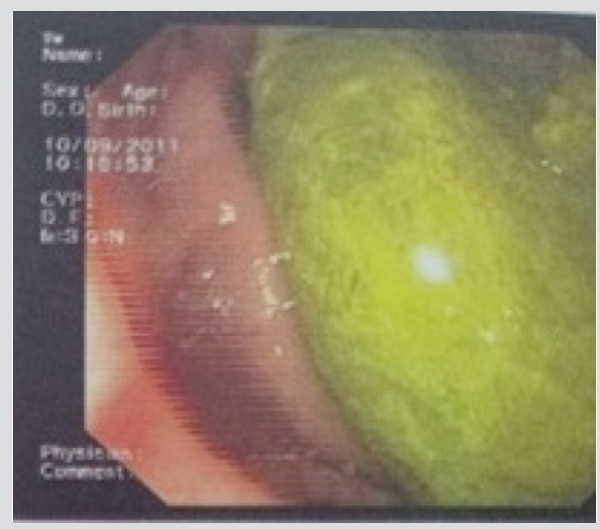

Figure 2: Endoscopic image of the intragastric phytobezoar

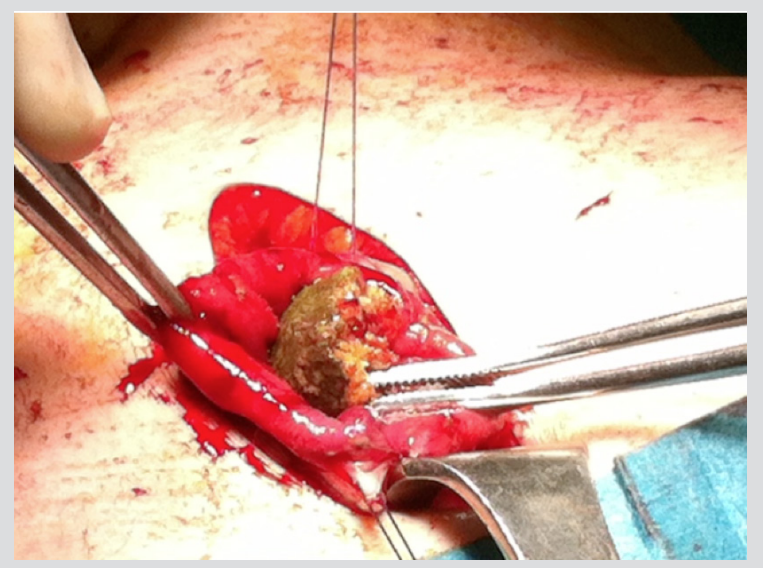

Figure 3: Surgical removal of the phytobezoar by gastrotomy 


\section{DISCUSSION}

Many bezoars are asymptomatic, so the number of reported cases underestimates their prevalence in the general population. In fact, bezoars were found in $0.4 \%$ of patients in two large endoscopic series ${ }^{[8]}$. The pathogenesis of bezoars is complex. The major risk factors for phytobezoar formation are edentulism, ingestion of indigestible material, anatomic alterations of the stomach and dysfunction in gastric motility (e.g. gastric surgery, diabetic gastroparesis) ${ }^{[9,10]}$. Subjects who have undergone vagotomy and partial gastrectomy show a reduced capacity of the stomach to fragment and digest food. In these subjects, the amount of gastric juice is reduced and peptic activity is decreased ${ }^{[11]}$. Also, acid-suppressing drugs that neutralize gastric acidity or inhibit gastric acid secretion could lead to an increased risk of phytobezoar development ${ }^{[9]}$. Furthermore, mixed connective tissue disease and hypothyroidism were reported as risk factors for bezoar formation $^{[12]}$.

The clinical presentation of bezoars is related to their location and usually includes nausea, vomiting, loss of appetite, abdominal discomfort or pain, and weight loss. Our patient, although complaining of all these symptoms for a long time, remained undiagnosed until hospitalization. The novelty of this case report lies in the detection of a phytobezoar in an earlier decade of life in an edentulous adult man eating predominantly fruits and vegetables. In fact, the diagnosis of phytobezoars may be complex and usually depends on endoscopy.

Complications of bezoars include bleeding, ulcers, perforation, intussusceptions and bowel obstruction ${ }^{[13]}$. Bezoars can also develop in a duodenal diverticulum, thus causing cholestasis ${ }^{[14]}$.

Ultrasound (US) scan or computerized tomography (CT) can detect bezoars before surgery ${ }^{[15,16]}$. In a retrospective study by Ripollés et al., ${ }^{[15]}$ ultrasound was able to detect phytobezoars in $88 \%$ of patients with small bowel obstruction. Bezoar appears as a hyperechoic arclike surface with acoustic shadowing on ultrasound, and is hard to distinguish from gallstones. Although US or whole body CT scanning is not recommended for the initial assessment of patients with weight loss (e.g. by UpToDate), US imaging could be helpful, particularly in elderly individuals in whom bezoars are more likely to occur. On the other hand, abdominal CT imaging, while being diagnostic when an intraluminal mass with a mottled gas pattern is seen, as in our adult patient, could offer useful information to exclude a neoplastic cause of rapid weight loss associated with hyporexia, such as pancreatic or gastric cancer. Endoscopy, however, provides the most accurate tool for the identification and classification of bezoars ${ }^{[9]}$. Barium swallow, unfortunately, can only detect approximately $25 \%$ of bezoars found endoscopically ${ }^{[9]}$.

The treatment of phytobezoars includes gastric lavage, enzymatic dissolution, endoscopic procedures (e.g. fragmentation) and surgical removal[9,11,17,18]. Gastric lavage with $\mathrm{NaHCO}_{3}$ which has mucolytic activity, and penetration of $\mathrm{CO}^{2}$ bubbles into the surface of phytobezoars, could help digestion of the fibres ${ }^{[11]}$. Various agents such as cellulase, acetylcysteine, papain and Coca-Cola have been used to dissolve phytobezoars with variable efficacy ${ }^{[18-20]}$. Chemical dissolution requires a long time and complications (e.g. bleeding, gastric ulcers and electrolyte imbalance) may occur ${ }^{[21]}$. Endoscopic fragmentation and/or aspiration, however, represents the first line therapeutic option ${ }^{[22]}$. Nevertheless, removal of large gastric phytobezoars, as in our patient, may be difficult endoscopically because of their location. In these cases a surgical procedure is, therefore, the only option. Nirasawa et al. found that up to $80 \%$ of abdominal operations for bezoar removal could be performed laparoscopically ${ }^{[23]}$. Compared with open surgery, laparoscopic procedures are associated with minimal incision, less pain, reduced hospitalization and fewer complication ${ }^{[24,25]}$. However, our patient underwent uneventful open surgery because of the large size of the bezoar. In conclusion, unexplained vomiting and weight loss in patients with edentulism on a diet rich in fruits and vegetables, may be caused by phytobezoar. This should be taken into account, particularly in older patients, but could be rarely also be the case in younger individuals.

\section{REFERENCES}

1. Williams RS. The fascinating history of bezoars. Med J Aust 1986;145:613-614

2. Baudamant WW. Memoire sur des cheveux trouves dans l'estomac et dans les intestines grêles. J Med Chir Pharm 1779;52:507-514.

3. Allan JD, Woodruff J. Starch gastrolith. Report of a case of obstruction. N Engl J Med 1963;268:776-778.

4. Gaillard M, Tranchart H. Images in clinical medicine. Trichobezoar. N Engl J Med 2015;372:e8.

5. Hayes PG, Rotstein OD. Gastrointestinal phytobezoars: presentation and management. Can J Surg 1986;29:419-420.

6. Zhang RL, Yang ZL, Fan BG. Huge gastric disopyrobezoar: a case report and review of literatures. World J Gastroenterol 2008;14:152-154.

7. Verstandig AG, Klin B, Bloom RA, Hadas I, Libson E. Small bowel phytobezoars: detection with radiography. Radiology 1989;172:705-707.

8. Kadian RS, Rose JF, Mann NS. Gastric bezoars--spontaneous resolution. Am J Gastroenterol 1978;70:79-82.

9. Andrus $\mathrm{CH}$, Ponsky JL. Bezoars: classification, pathophysiology, and treatment. Am J Gastroenterol 1988;83:476-478.

10. Walk L. Phytobezoar in the gastric stump; report of a case and discussion of therapy. Arch Intern Med (Chic) 1949;84:824-835.

11. Saeed ZA, Rabassa AA, Anand BS. An endoscopic method for removal of duodenal phytobezoars. Gastrointest Endosc 1995;41:74-76.

12. Mangold D, Woolam GL, Garcia-Rinaldi R. Intestinal obstruction due to phytobezoars: observations in two patients with hypothroidism and previous gastric surgery. Arch Surg 1978;113:1001-1003. 


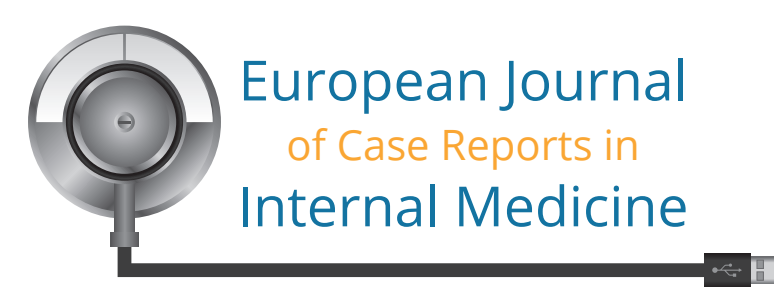

13. Rees M. Intussusception caused by multiple trichobezoars: a surgical trap for the unwary. Br J Surg 1984;71:721.

14. Seyrig JA, Chambon J, Fritsch J, Berger M, Liguory C, Chousterman M. Cholestasis caused by an intradiverticular bezoar. Endoscopic treatment. Gastroenterol Clin Biol 1989;13:741-743.

15. Ripollés T, García-Aguayo J, Martínez MJ, Gil P. Gastrointestinal bezoars: sonographic and CT characteristics. AJR Am J Roentgenol 2001;177:65-69.

16. Gayer G, Jonas T, Apter S, et al. Bezoars in the stomach and small bowel--CT appearance. Clin Radiol 1999;54:228-232.

17. Gáyá J, Barranco L, Llompart A, Reyes J, Obrador A. Persimmon bezoars: a successful combined therapy. Gastrointest Endosc 2002;55:581-583.

18. Ladas SD, Triantafyllou K, Tzathas C, Tassios P, Rokkas T, Raptis SA. Gastric phytobezoars may be treated by nasogastric Coca-Cola lavage. Eur J Gastroenterol Hepatol 2002;14:801-803.

19. Heinz-Erian P, Klein-Franke A, Gassner I, et al. Disintegration of large gastric lactobezoars by N-acetylcysteine. J Pediatr Gastroenterol Nutr 2010;50:108-110.

20. Lee BJ, Park JJ, Chun HJ, et al. How good is cola for dissolution of gastric phytobezoars? World J Gastroenterol 2009;15:2265-2269.

21. Koulas SG, Zikos N, Charalampous C, Christodoulou K, Sakkas L, Katsamakis N. Management of gastrointestinal bezoars: an analysis of 23 cases. Int Surg 2008;93:95-98.

22. Blam ME, Lichtenstein GR. A new endoscopic technique for the removal of gastric phytobezoars. Gastrointest Endosc 2000;52:404-408.

23. Nirasawa Y, Mori T, Ito Y, Tanaka H, Seki N, Atomi Y. Laparoscopic removal of a large gastric trichobezoar. J Pediatr Surg 1998;33:663-665.

24. Yau KK, Siu WT, Law BK, Cheung HY, Ha JP, Li MK. Laparoscopic approach compared with conventional open approach for bezoar-induced small-bowel obstruction. Arch Surg 2005;140:972-975

25. Song KY, Choi BJ, Kim SN, Park CH. Laparoscopic removal of gastric bezoar. Surg Laparosc Endosc Percutan Tech 2007;17:42-44. 